\title{
Finite element analysis of dental implants with validation: to what extent can we expect the model to predict biological phenomena? A literature review and proposal for classification of a validation process
}

\author{
Yuanhan Chang ${ }^{1 *} \mathbb{D}$, Abhijit Anil Tambe ${ }^{2}$, Yoshinobu Maeda', Masahiro Wada ${ }^{1}$ and Tomoya Gonda ${ }^{1}$
}

\begin{abstract}
A literature review of finite element analysis (FEA) studies of dental implants with their model validation process was performed to establish the criteria for evaluating validation methods with respect to their similarity to biological behavior. An electronic literature search of PubMed was conducted up to January 2017 using the Medical Subject Headings "dental implants" and "finite element analysis." After accessing the full texts, the context of each article was searched using the words "valid" and "validation" and articles in which these words appeared were read to determine whether they met the inclusion criteria for the review. Of 601 articles published from 1997 to 2016, 48 that met the eligibility criteria were selected. The articles were categorized according to their validation method as follows: in vivo experiments in humans $(n=1)$ and other animals $(n=3)$, model experiments $(n=32)$, others' clinical data and past literature $(n=9)$, and other software $(n=2)$. Validation techniques with a high level of sufficiency and efficiency are still rare in FEA studies of dental implants. High-level validation, especially using in vivo experiments tied to an accurate finite element method, needs to become an established part of FEA studies. The recognition of a validation process should be considered when judging the practicality of an FEA study.
\end{abstract}

Keywords: Finite element analysis, Dental implant, Validation, Verification

\section{Review}

Background

Finite element analysis (FEA) has been applied to investigate dental implant designs, the structure and material of the superstructure, and the stability of the surrounding bone $[1,2]$. According to PubMed, only 10 FEA studies of dental implants were published in 1990, while 102 papers were published in 2014.

FEA has become an increasingly useful tool in the past few decades. In the medical field, the behavior of any

\footnotetext{
* Correspondence: tyou@dent.osaka-u.ac.jp

'Department of Prosthodontics, Gerodontology and Oral Rehabilitation, Osaka University Graduate School of Dentistry, 1-8 Yamadaoka, Suita, Osaka 565-0871, Japan

Full list of author information is available at the end of the article
}

structure or tissue under a particular stimulation can be evaluated using FEA, and biomechanical changes in the tissues can be analyzed. Additionally, FEA allows for measurement of the stress distribution inside of the bone and various dental implant designs during mastication; such measurements are impossible to perform in vivo $[1,2,3]$.

A large number of FEA regarding dental implant and bone were published in these decades; however, the precision and accuracy of those studies in silico are still questionable. In 2009, Dumont et al. [4] indicated that FEA studies of biological structures should be validated experimentally whenever possible. Hannam [5] stated that the minimum requirements of FEA studies should include comparisons with data from other work or any data that can be gleaned from the living subjects being modeled. 
According to the American Society of Mechanical Engineers Committee on verification and validation in computational solid mechanics, verification is defined as "the process of determining that a computational model accurately represents the underlying mathematical model and its solution," while validation is defined as "the process of determining the degree to which a model is an accurate representation of the real world from the perspective of the intended uses of the model." In simple terms, verification is the process of "solving the equations right," whereas validation is the process of "solving the right equations" [6-9]. Validation is a process by which computational predictions are compared with experimental data in an effort to assess the modeling error [6-9]. The sole purpose of these "experiments" is to produce data for comparison with model predictions rather than to address specific scientific hypotheses.

FEA studies with validation have recently become more common in the biomechanical field. FEA validations can be divided into two types: (1) direct validation, which involves experiments on the quantities of interest (from basic material characterizations to hierarchical system analysis such as model experiments and in vitro experiments), and (2) indirect validation, which involves the use of literature or the results of previous clinical studies. Indirect validation is clearly less favored than direct validation because of its uncertain experimental quality, sources of error, and high degree of variability. However, indirect validation may be unavoidable in FEA because no concrete biological outcome can be directly attributed to most FEA studies of force distribution; thus, it is difficult to generate outcome data for comparison with experimental data. Therefore, FEA studies should include a validation method to prove the close similarity of the results to the actual clinical situation. Validation is the process of "solving the right equations" [6-9] and comparing computational predictions with experimental data (the "gold standard") in an effort to assess the modeling error.

The purpose of this literature review of FEA studies was to examine their model validation process and establish the criteria for evaluating validation methods with respect to their similarity to biological behavior.

\section{Materials and methods}

All studies included in this review (eligibility criteria) were FEA studies of the stress distribution of dental implants and surrounding bone using any type of validation method, and all were published in English. The exclusion criteria were publication in a language other than English, appearance of the word "validation" only in the references, no mention of the validation method for numerical FEA analysis, and mentioning of the requirement for validation without conduction of the actual validation.
An electronic literature search of PubMed was conducted up to January 2017 using the Medical Subject Headings "dental implants" and "finite element analysis." After accessing the full text, the full context was searched using the words "valid" and "validation," and all articles containing these words were read to determine whether they met the inclusion criteria. The selected articles were then read and summarized, and the validation techniques used in each article were assessed and categorized in a hierarchy (Fig. 1).

\section{Results}

In total, 601 articles were obtained from the PubMed electronic search using the Medical Subject Headings "dental implants" and "finite element analysis." After excluding articles for which the full text could not be accessed $(n=69)$ and that were not written in English $(n=10), 522$ articles remained. These articles were searched using the terms "validation," "validity," and "valid" to determine whether the studies had performed a validation; after this process, 122 articles remained. These 122 articles were read, and 47 that met the eligibility criteria were selected and are summarized in Table 1. These articles were all FEA studies published from 1997 to 2016. The articles were categorized according to the method of validation as follows: in vivo experiments, model experiments, use of others' clinical data or literature, and other software (Figs. 2 and 3).

Based on the validation methods described in the articles, the top portion of the validation hierarchy comprised studies that used a customized clinical method in a human for validation [10]. The next level of the hierarchy comprised studies that used models for validation, including animal models [11-13] and mechanical experiments. Mechanical experiments were divided according to the material used for bone models and the techniques used for testing those models. The materials were divided into homogenous bone, heterogeneous bone, and artificial materials such as acrylic, polyurethane, plastic bone material, and others. Various validation methods were used in studies that employed mechanical testing of bone models using these specific artificial materials, such as digital image correction [11], photo-elastic stress analysis [15], and use of a strain gauge test attached to a model (this was the most commonly used method, described in 15 of 48 articles). These techniques also involved measurement of the implant displacement and fatigue testing of an implant body. The next level of the hierarchy comprised studies that used literature or clinical data from other articles to compare with results of FEA. The final level comprised studies that used other computer software for support but did not perform an actual experiment.

We classified all validation processes based on their similarity to real biomechanical behaviors into the following hierarchy (levels A to G) (Fig. 2): 


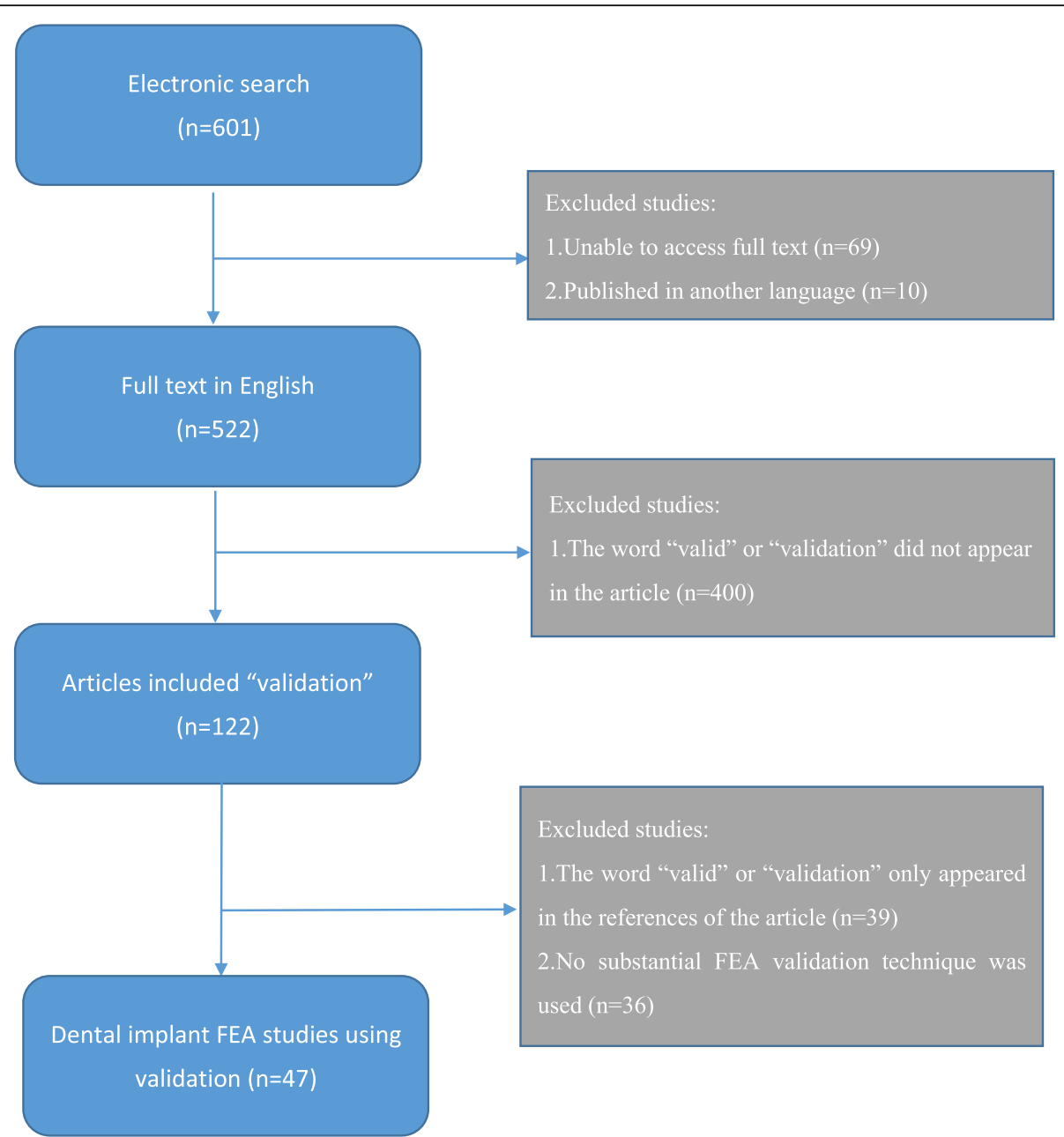

Fig. 1 Flowchart of literature review. An electronic literature search of PubMed was conducted up to January 2017 using the Medical Subject Headings "dental implants" and "finite element analysis." After accessing the full texts, the context of each article was searched using the words "valid" and "validation" and articles in which these words appeared were read to determine whether they met the inclusion criteria for the review

Level A: performed in vivo (human bodies) $(n=1)[10]$

The top level of the hierarchy, level A, includes in vivo methods of FEA validation conducted in humans. In 2006, Heckmann et al. [10] quantified the degree of stress that occurs in the bone around the implants as a result of fixation of cemented and screw-retained fixed partial dentures. They used a computer-aided design (CAD) model of an implant embedded in a bone block for FEA, and strain gauge experiments were performed under the same loading conditions with the use of a resin bone model and a human being for validation.

Level B: performed in vivo (heterogeneous animals) $(n=3)[11-13]$

Three studies conducted animal experiments for FEA validation. In 2009, Hou et al. [12] conducted an FEA validation study involving rats to assess the histological change in the mechanical environment surrounding loaded and unloaded implants. In 1997, Natali et al. [11] performed a validation study in which they compared the influence of axial and nonaxial forces on the bone tissue surrounding oral implants placed in dogs. Both research groups used computed tomography data and CAD techniques to create an FEA model. Similarly, in 2015, Cha et al. [13] used murine femurs to place implants with low and high insertion torques for FEA validation.

Level C: model experiment performed using part of a cadaver $(n=4)[16-19]$

Level D: model experiment performed using heterogeneous bone $(n=5)$ [20-24]

The next two levels in the hierarchy comprised in vivo model experiments on a section of a cadaver (level C) and the bone of heterogeneous animals (level D). Most 


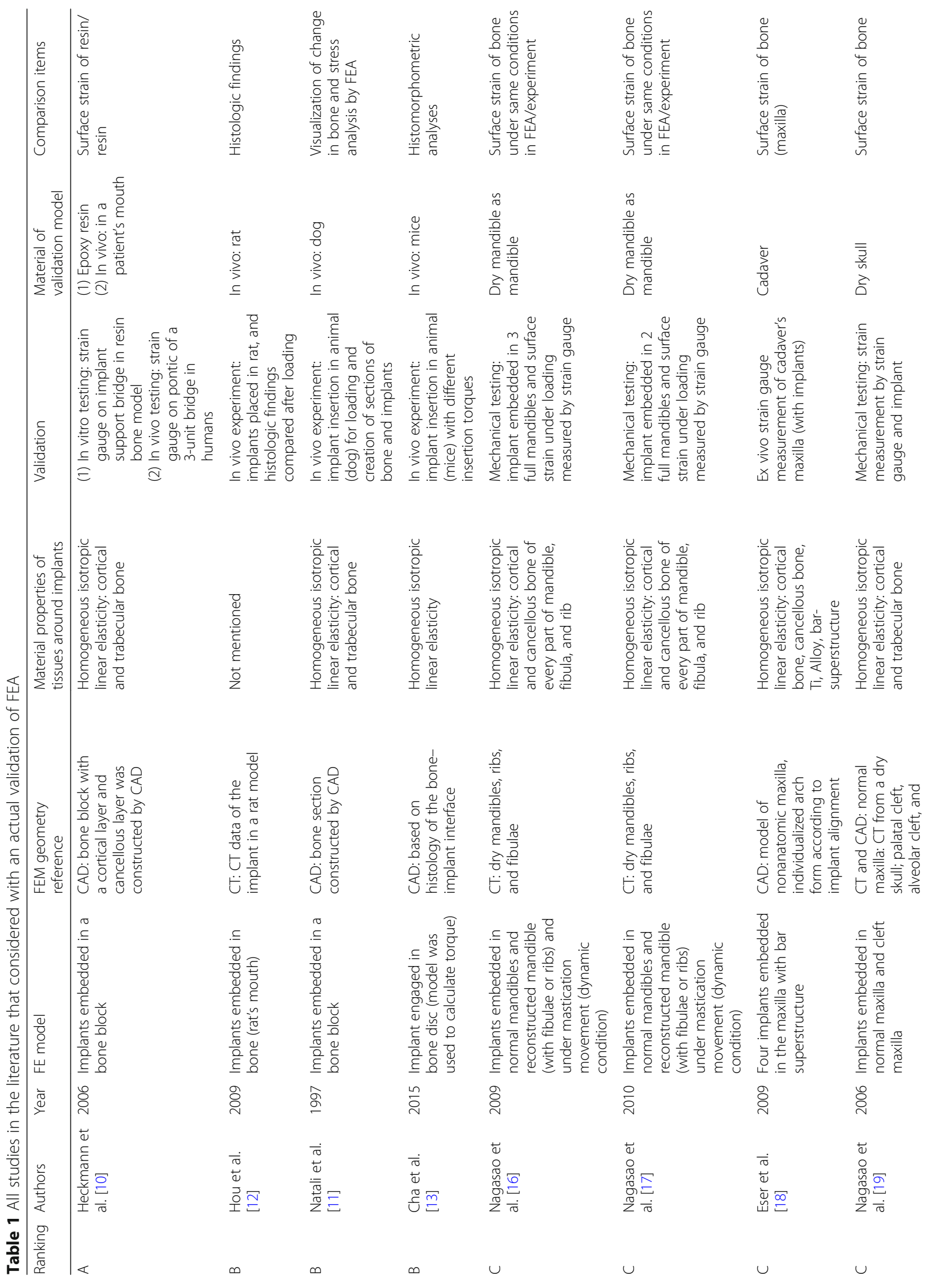




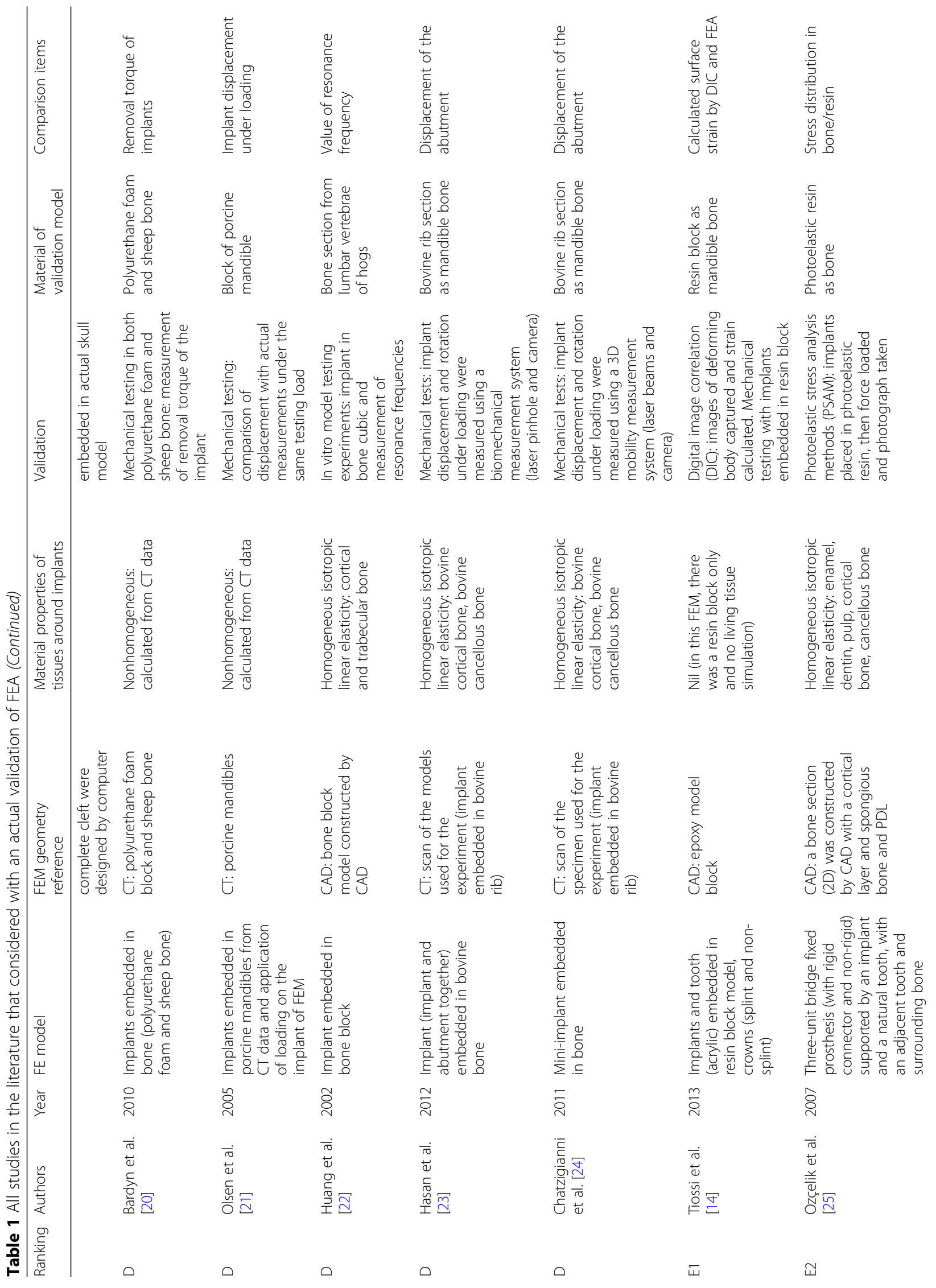




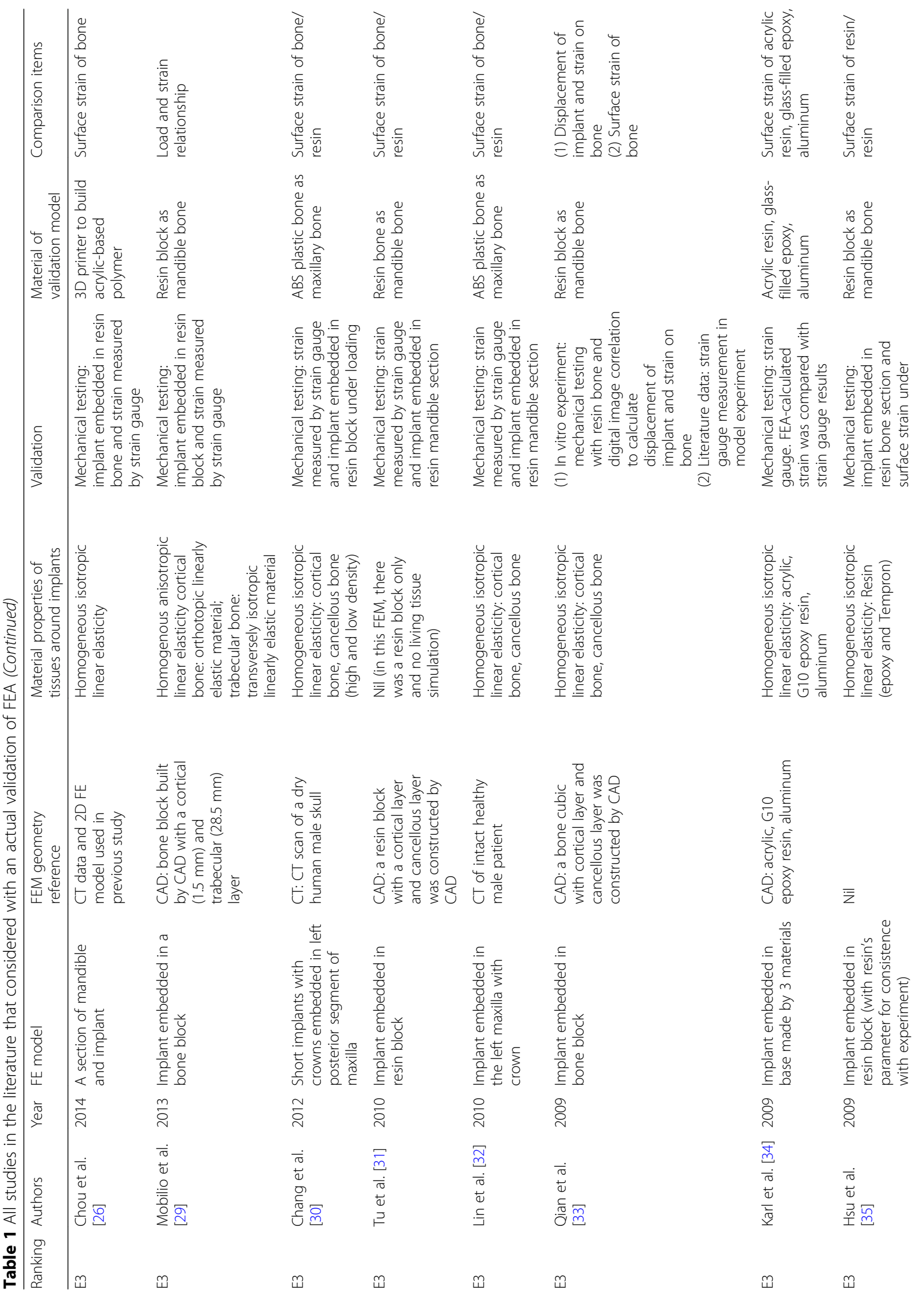




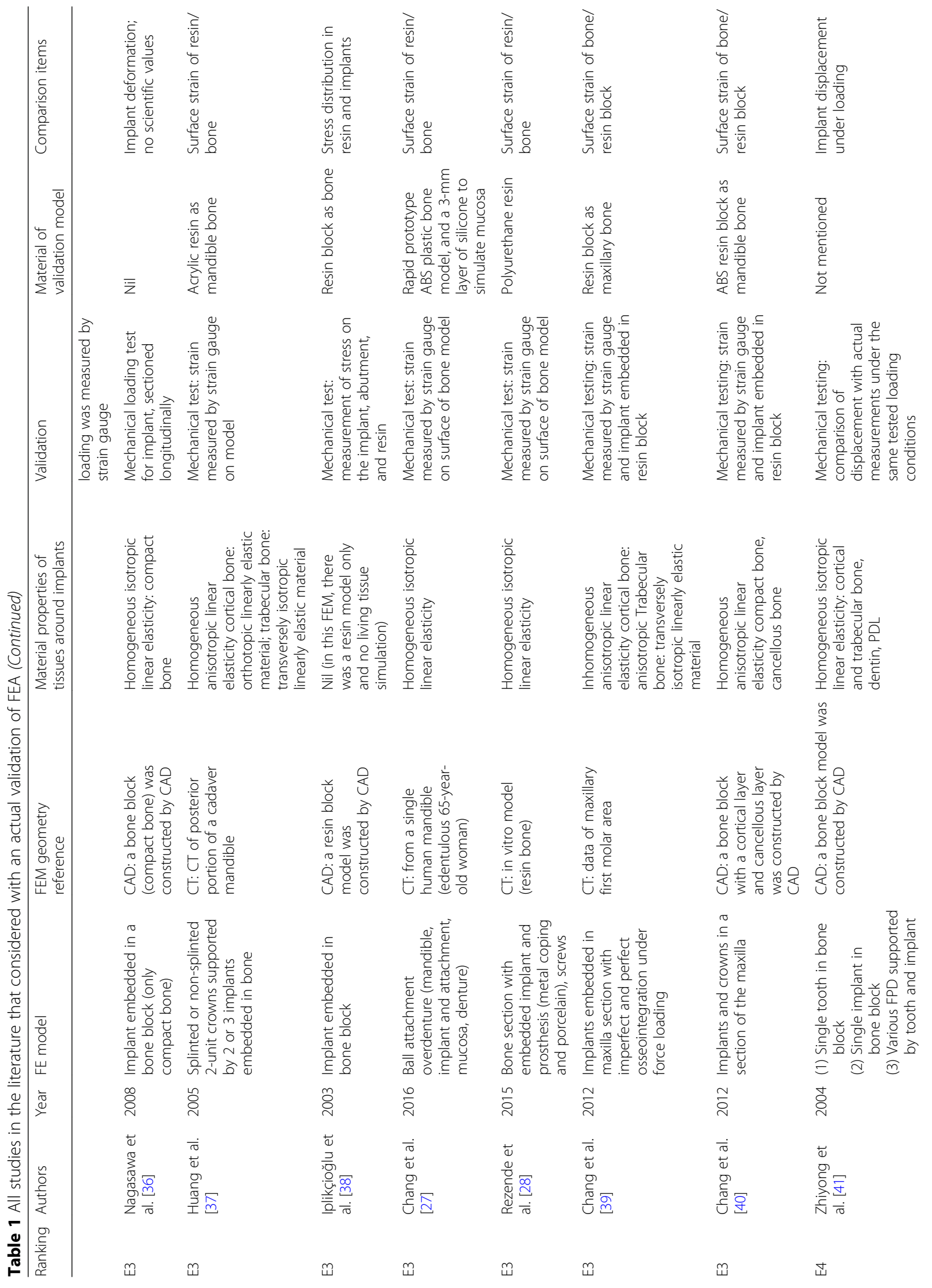




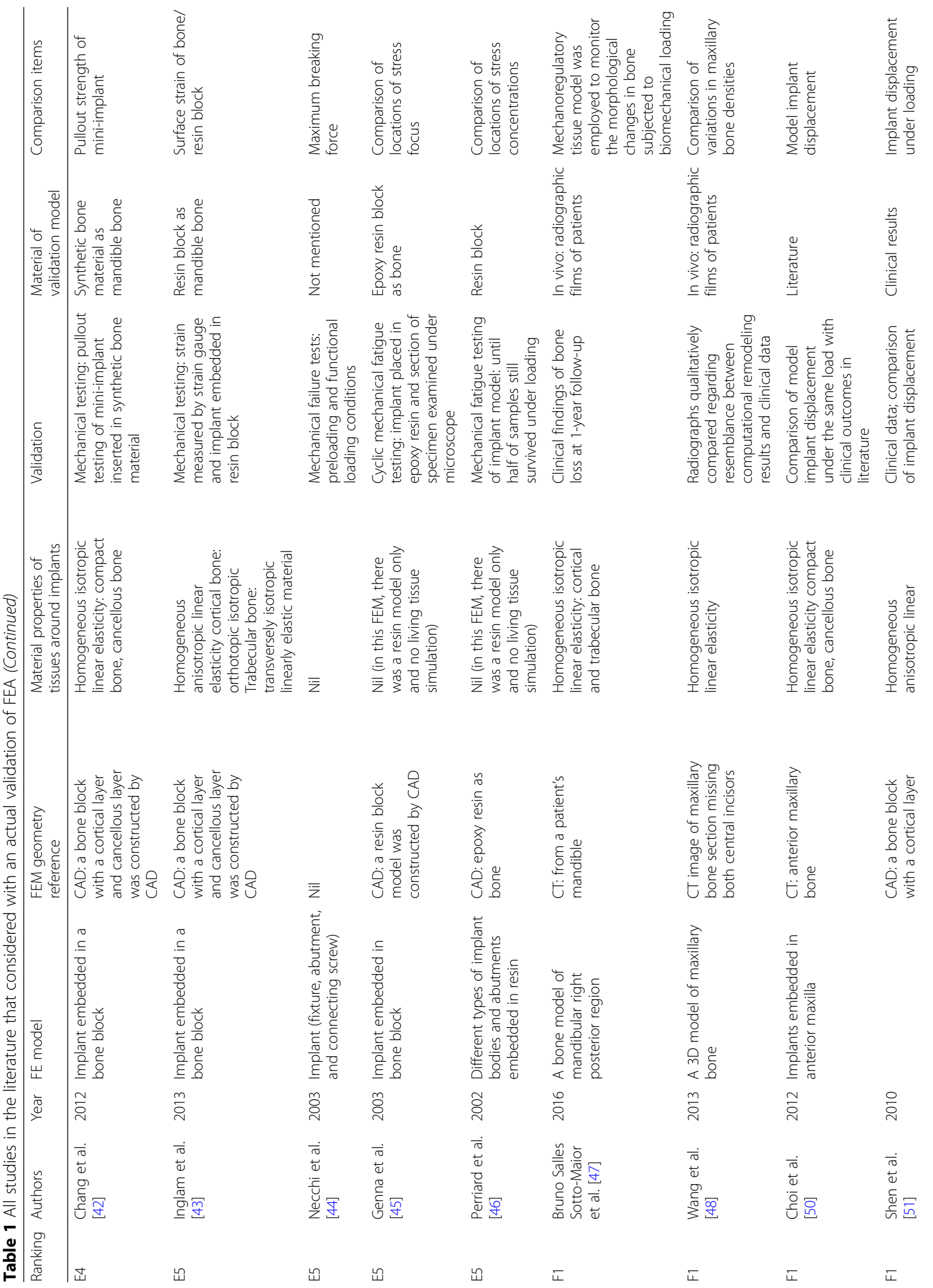




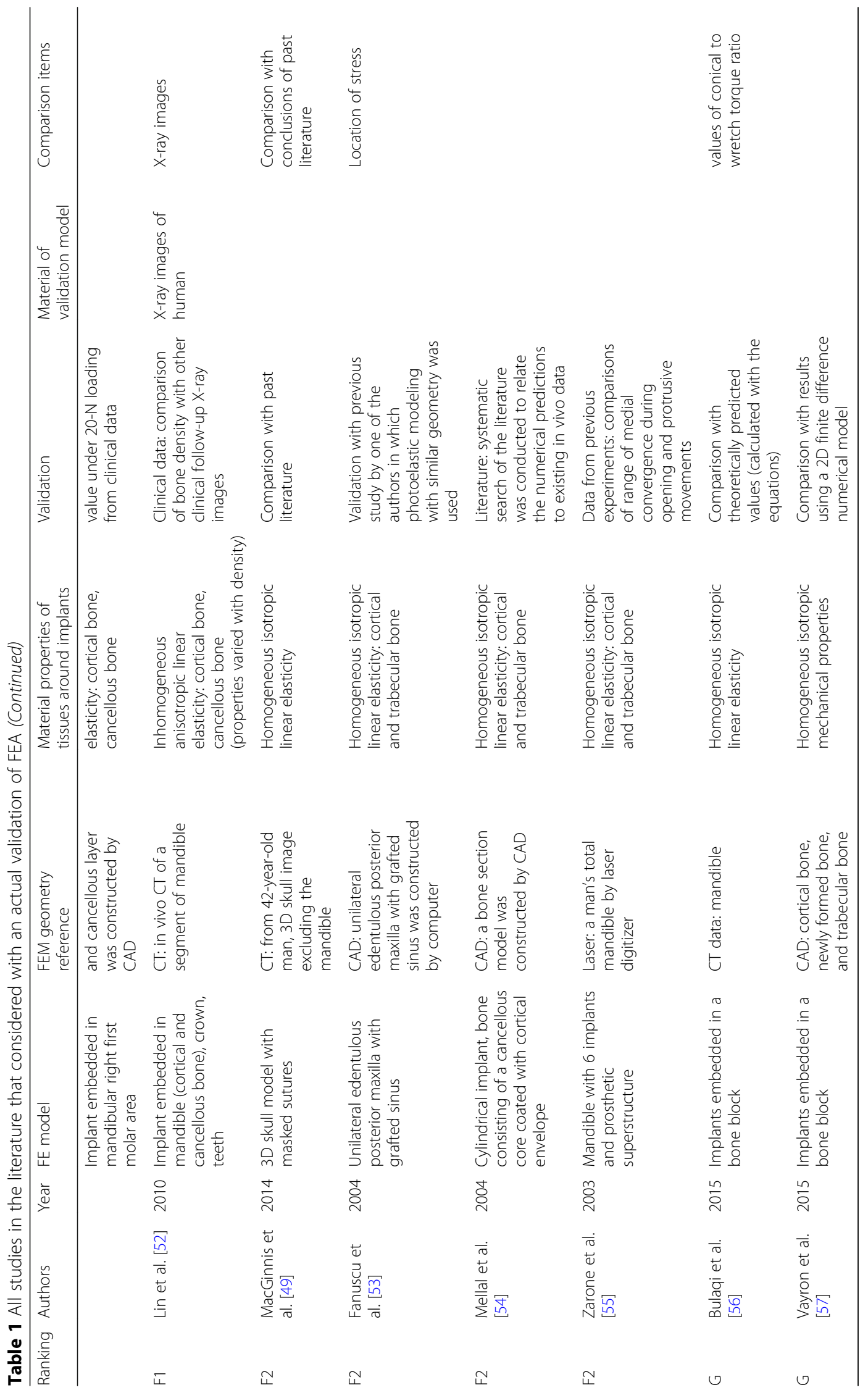




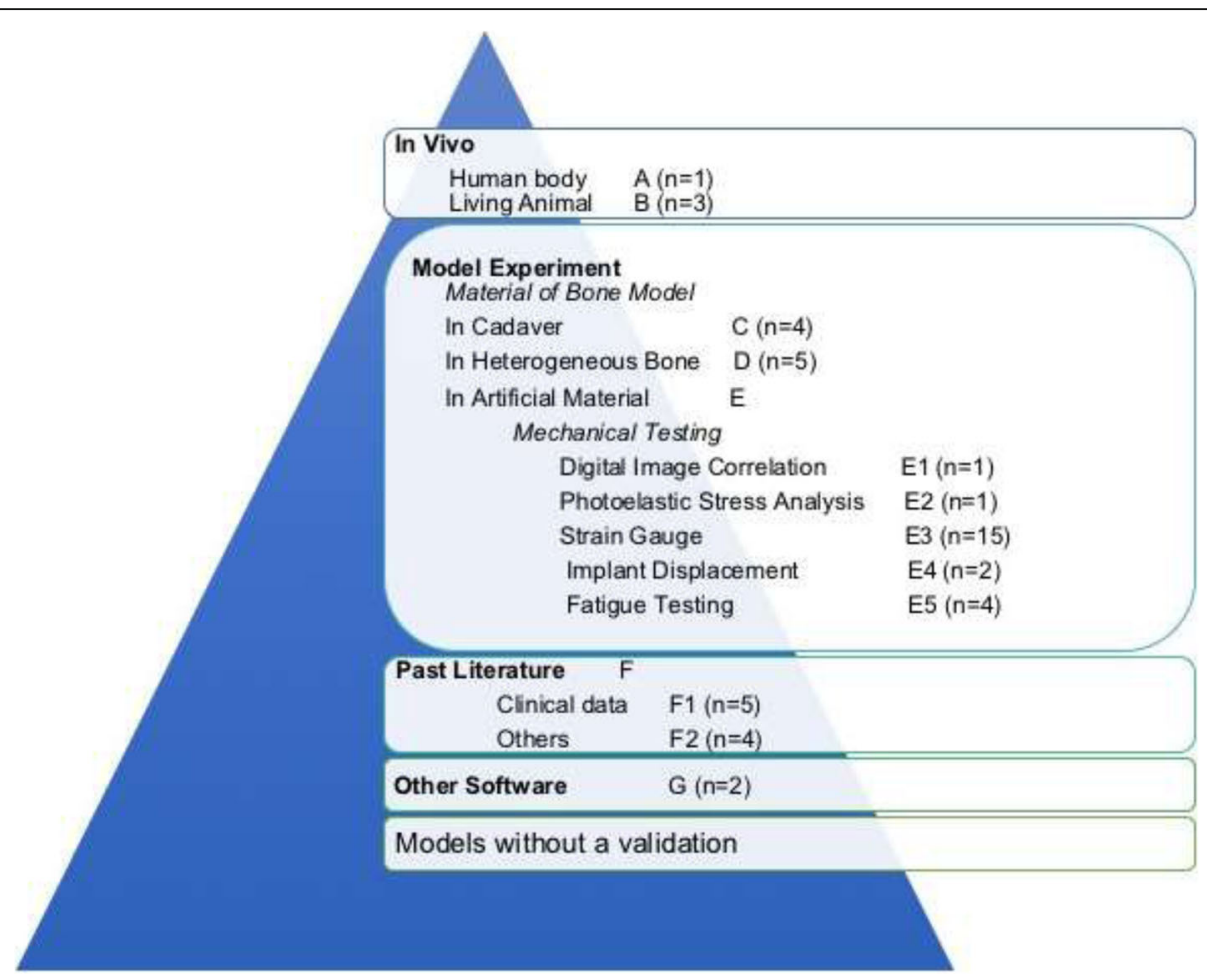

Fig. 2 Hierarchy of validations based on their similarity to real biomechanical behaviors. The articles $(n=47)$ were categorized according to their validation method as follows: in vivo experiments in humans $(n=1)$ and other animals $(n=3)$, model experiments $(n=32)$, others' clinical data and past literature $(n=9)$, and other software $(n=2)$

of these studies involved mechanical testing, such as recording strain by a strain gauge attached to a dry skull or a section of bovine, porcine, or sheep bone. Bardyn et al. [20] compared the FEA-predicted removal torque with that measured using sheep bone and polyurethane foam as a validation technique. Olsen et al. [21] scanned a porcine mandible to create an FEA model and compared the FEA-predicted implant displacement with that measured on the same porcine mandible as a validation technique. Additionally, in 2002, Huang et al. [22] determined the vibrating behavior of a dental implant under various surrounding bone conditions using bone

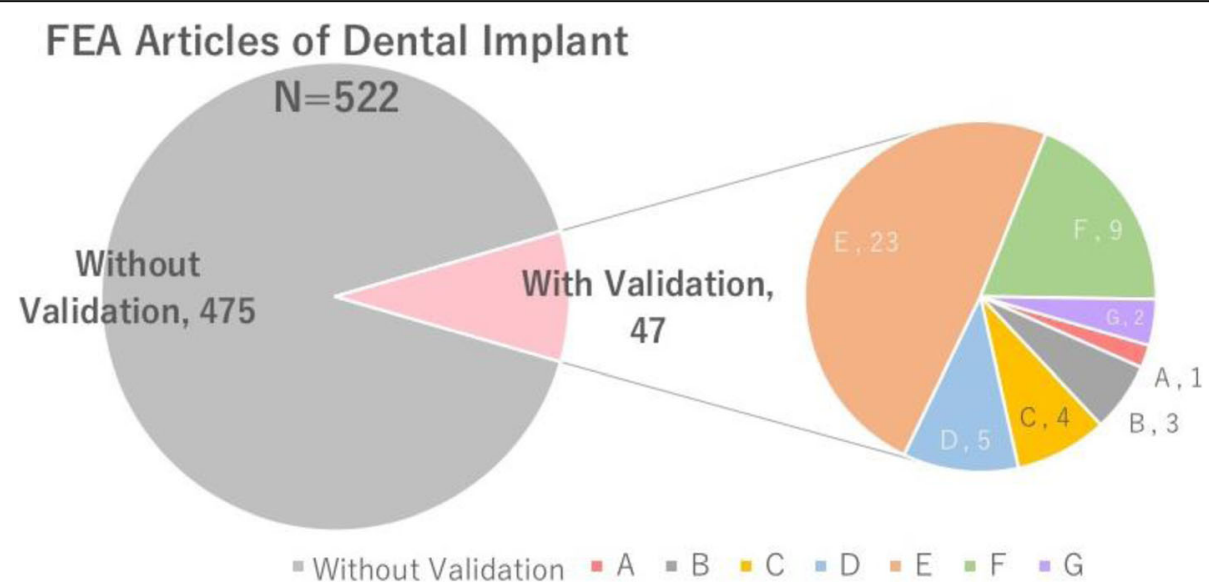

Fig. 3 Proportion of dental implant FEA articles with a validation. (Left) Among totally 522 FEA articles of dental implants which we were able to access English full text up to January 2017, there are only 47 articles with a validation. (Right) The articles with a validation were categorized according to their validation method as follows levels: A, in vivo (human bodies); B, performed in vivo (heterogeneous animals); , model experiment performed using part of a cadaver; $D$, model experiment performed using heterogeneous bone; $E$, model experiment performed using artificial materials; F, comparison with past literature; and G, performed with other software $(n=2)$ 
sections from hogs and FEA. The resonance frequency was compared between the two techniques, but in this case, FEA seemed more likely to serve as a validation technique to support the results of the model experiment.

Level E: model experiment performed using artificial materials $(n=23)[14,25,26-46]$

Artificial materials such as acrylic resin, polyurethane, or plastic bone models were commonly used as embedded "bone" implants in validation experiments. Level $\mathrm{E}$ includes the use of special materials and specific methods to measure the force distribution and photoelastic resin as well as a technique called digital image correlation described by Tiossi et al. [14] in 2013. Comparisons of these artificial materials is difficult because it is challenging to determine how much more accurate one technique is over another technique. Even after subcategorizing the techniques from E1 to E5, we found that no one technique was superior to any other.

Level F: performed by comparison with past literature $(n=9)[47-55]$

Validations in this level involve comparison of FEA with clinical data (F1) or other literature (F2). Most such studies compared FEA with "similar" conditions in patients, but either the comparisons were not customized or indirect and ill-defined clinical results (e.g., bone resorption volume in length or radiographic X-ray images) were compared with force in FEA. Level F2 includes validation using past literature with similar results or conclusions that were mostly summarized in few words in the "Discussion" section of an article.

Level G: performed by comparison with other software $(n=2)[56,57]$

The last level, level G, includes validation performed by another type of computer software such as twodimensional FEA, i.e., an FEA model built in a computer is validated by another computer simulation or calculated values.

\section{Discussion}

The use of FEA for dental implants and surrounding bone has increased during the past few decades. Our PubMed search using the terms "dental implants" and "finite element analysis" revealed about 450 papers published in the past 10 years. However, FEA studies of implants using validation experiments are comparatively rare. While prior studies had effectively outlined the importance of validation in biomechanical FEA, no reviews of studies that applied validation to computational biomechanics of dental implants have been performed.

Table 1 shows all studies in the literature that considered the need for validation of FEAs. According to these studies, we established a hierarchy based on the evidence level of the validations (A to G, i.e., high to low) (Fig. 2).

Level A: validation using living humans

Level B: validation using living heterogeneous animals

Levels $C$ and $D$ : validation using homogenous and heterogeneous bone

Level E: validation using artificial bone materials

Level F: validation using past literature

Level G: validation using other software

FEA using model verification cannot be considered to be a validation method for entire study. Model verification should be performed to ensure accurate FEA; however, finite element models verified with clinical data such as a patient's computed tomography findings are categorized in a low level of validation or without validation. For this reason, studies that used only model verification (some studies may called it by "model validation") were not included in our review [58-62].

Many recent papers $[10-12,14,15,25-31,33,35,36$, $39,41-45,47,48,50-52,54,55,58-74]$ have described the use of FEA to evaluate the stress distribution of implant fixtures and surrounding bone, with a particular focus on different fixture lengths, shapes, connection designs, and prostheses. However, most such studies [15, 58-74] were performed without validation executed under the same conditions with the FEA. The following questions are worthy of consideration by oral scientists and clinicians: Can a finite element model really create a virtual condition simulating the biomechanical behavior of the craniomandibular system? To what extent can we predict biological activities with finite element models [9]?

The complexity of living organisms and internal biological phenomena is impossible to fully and precisely duplicate with individual-level specificity using a computer. However, we can evaluate the limitations of current technology and build a model with the highest level of evidence possible.

Because of the limitations of computer technology, most FEA models [75-79] simplify the skeletal muscle architecture in terms of a uniform fiber length, pennation angle, and line of action and represent the architecture using a Hill-based muscle model. However, how well the modeling of skeletal muscles as one-dimensional strings represents the 
behavior of the full three-dimensional muscles remains unknown. Reducing the complexity of the muscles to strings entirely neglects the variations in muscle density (deformation) and structure during the complex movement of real muscle specimens, which is difficult to acquire.

This review focused on validation of FEA and established a hierarchy of validation techniques from high to low as a reference for further FEA studies. However, due to the limitations of this study, the boundary conditions and finite element method (FEM) settings were not considered. For example, some research may have involved high-level validation performed in vivo, but the original FEM model was built by CAD using only a simple flat two-layer bone and without any model verification. Some other studies used a simulated bone (computed tomography data from homogeneous, heterogeneous, or artificial materials) as an FEM geometry reference and performed the validation on that material only, without seeking to perform validation using a more realistic material. Both the use of a detailed, accurate model that closely resembles the real condition and the performance of validation to prove its accuracy are important. As computer technology has progressed, model verification has become more sophisticated and complicated; however, validation still should not be ignored.

While conducting this review, we also considered future efforts. There are two types of FEA studies: time-dependent studies, which have a validity period within which the process must take place, and timeindependent studies, which have no validity period but only analyze the stress distribution at a single point in time. To date, several biomechanical studies have been published with time-independent analysis [10-12, 14, $15,25-31,33,35,36,39,41-45,47,48,50-52,54,55$, $58-74,80]$ (e.g., examination of bone resorption underneath the denture base, analysis of the instant stress distribution of a dental implant, and the bones or components of an artificial knee joint). Maeda and Wood [80] simulated a bone-dependent bone resorption process using an FEM model and shape-optimization algorithm.

To explain or analyze the mechanical properties involved in biological phenomena such as motor tasks (mastication, walking, or heart contraction), a time-dependent finite element model may provide a more realistic view. However, if time-dependent performance criteria are considered (the most common is to clarify the influence of musculoskeletal structure on function or the performance of a motor task), dynamic optimization and boundary conditions are required. This means that a much more complex model including many parameters and properties must be built, despite some of these real-world physiological data being unknown. This difficulty may explain why time-dependent models of mastication for FEA are rare.

\section{Conclusions}

1. High-level validation of FEA using in vivo experiments is still rare in the dental implant field.

2. It is necessary to clearly indicate the validation process of the model when a study using FEA is presented.

3. The hierarchy proposed in this study based on the evidence level of the validations can be applied to evaluate the clinical significance of studies using FEA.

Authors' contributions

YC and YM studied the concept and design of the study. YC, AAT, and TG contributed to the acquisition of the data. YC, AAT, and MW analyzed and interpreted the data. YC drafted the manuscript. YC and YM critically revised the article. All authors read and approved the final manuscript.

\section{Competing interests}

Yuanhan Chang, Abhijit Anil Tambe, Yoshinobu Maeda, Masahiro Wada, and Tomoya Gonda declare that they have no competing interests.

\section{Publisher's Note}

Springer Nature remains neutral with regard to jurisdictional claims in published maps and institutional affiliations.

\section{Author details}

'Department of Prosthodontics, Gerodontology and Oral Rehabilitation, Osaka University Graduate School of Dentistry, 1-8 Yamadaoka, Suita, Osaka 565-0871, Japan. ${ }^{2}$ Mahatma Gandhi Vidyamandir's Karmaveer Bhausaheb Hiray Dental College \& Hospital, Mumbai Agra Road, Panchwati, Nashik, Maharashtra, India.

Received: 5 November 2017 Accepted: 10 January 2018

Published online: 08 March 2018

\section{References}

1. Van Staden RC, Guan H, Loo YC. Application of the finite element method in dental implant research. Comput Methods Biomech Biomed Engin. 2006;: $9257-70$.

2. Maminskas J, Puisys A, Kuoppala R, Raustia A, Juodzbalys G. The prosthetic influence and biomechanics on peri-implant strain: a systematic literature review of finite element studies. J Oral Maxillofac Res. 2016;7:e4.

3. Gass SI. Decision-adding models: validation, assessment and related issues for policy analysis. Oper Res. 1983;31:603-31.

4. Dumont ER, Grosse IR, Slater GJ. Requirements for comparing the performance of finite element models of biological structures. J Theor Biol. 2009;256:96-103.

5. Hannam AG. Current computational modelling trends in craniomandibular biomechanics and their clinical implications. J Oral Rehabil. 2011;38:217-34.

6. Boehm BW. Software engineering economics. Englewood Cliffs: Prentice Hall; 1981.

7. Blottner FG. Accurate Navier-Stokes results for the hypersonic flow over a spherical nosetip. AIAA J Spacecr Rocket 1990;27:113-122.

8. Anderson AE, Ellis BJ, Weiss JA. Verification, validation and sensitivity studies in computational biomechanics. Comput Methods Biomech Biomed Engin. 2007;10: $171-84$

9. Viceconti $M$, Olsen $S$, Nolte LP, Burton $K$. Extracting clinically relevant data from finite element simulations. Clin Biomech (Bristol, Avon). 2005:20:451-4.

10. Heckmann SM, Karl M, Wichmann MG, Winter W, Graef F, Taylor TD. Loading of bone surrounding implants through three-unit fixed partial denture fixation: a finite-element analysis based on in vitro and in vivo strain measurements. Clin Oral Implants Res. 2006;17:345-50.

11. Natali AN, Meroi EA, Williams KR, Calabrese L. Investigation of the integration process of dental implants by means of a numerical analysis of dynamic response. Dent Mater. 1997;13:325-32.

12. Hou X, Weiler MA, Winger JN, Morris JR, Borke JL. Rat model for studying tissue changes induced by the mechanical environment surrounding loaded titanium implants. Int J Oral Maxillofac Implants. 2009;24:800-7.

13. Cha JY, Pereira MD, Smith AA, Houschyar KS, Yin X, Mouraret S, et al. Multiscale analyses of the bone-implant interface. J Dent Res. 2015;94:482-90. 
14. Tiossi R, Vasco MA, Lin L, Conrad HJ, Bezzon OL, Ribeiro RF, et al. Validation of finite element models for strain analysis of implant-supported prostheses using digital image correlation. Dent Mater. 2013;29:788-96.

15. Alrbata RH, Yu W, Kyung HM. Biomechanical effectiveness of cortical bone thickness on orthodontic microimplant stability: an evaluation based on the load share between cortical and cancellous bone. Am J Orthod Dentofac Orthop. 2014;146:175-82

16. Nagasao T, Miyamoto J, Kawana H. Biomechanical evaluation of implant placement in the reconstructed mandible. Int J Oral Maxillofac Implants. 2009;24:999-1005.

17. Nagasao T, Miyamoto J, Tamaki T, Kawana H. A comparison of stresses in implantation for grafted and plate-and-screw mandible reconstruction. Oral Surg Oral Med Oral Pathol Oral Radiol Endod. 2010;109:346-56.

18. Eser A, Akça K, Eckert S, Cehreli MC. Nonlinear finite element analysis versus ex vivo strain gauge measurements on immediately loaded implants. Int J Oral Maxillofac Implants. 2009;24:439-46.

19. Nagasao T, Miyamoto J, Jin H, Tamaki T, Isshiki Y, Kaneko T, et al. The dynamics in implantation for patients with clefts. Cleft Palate Craniofac J. 2006;43:84-91.

20. Bardyn T, Gédet P, Hallermann W, Büchler P. Prediction of dental implant torque with a fast and automatic finite element analysis: a pilot study. Oral Surg Oral Med Oral Pathol Oral Radiol Endod. 2010;109:594-603.

21. Olsen S, Ferguson SJ, Sigrist C, Fritz WR, Nolte LP, Hallermann W, et al. A novel computational method for real-time preoperative assessment of primary dental implant stability. Clin Oral Implants Res. 2005;16:53-9.

22. Huang HM, Lee SY, Yeh CY, Lin CT. Resonance frequency assessment of dental implant stability with various bone qualities: a numerical approach. Clin Oral Implants Res. 2002;13:65-74.

23. Hasan I, Röger B, Heinemann F, Keilig L, Bourauel C. Influence of abutment design on the success of immediately loaded dental implants: experimental and numerical studies. Med Eng Phys. 2012;34:817-25.

24. Chatzigianni A, Keilig L, Duschner H, Götz H, Eliades T, Bourauel C. Comparative analysis of numerical and experimental data of orthodontic mini-implants. Eur J Orthod. 2011;33:468-75.

25. Ozçelik T, Ersoy AE. An investigation of tooth/implant-supported fixed prosthesis designs with two different stress analysis methods: an in vitro study. J Prosthodont. 2007;16:107-16.

26. Chou IC, Lee SY, Jiang CP. Effects of implant neck design on primary stability and overload in a type IV mandibular bone. Int J Numer Method Biomed Eng. 2014;30:1223-37.

27. Chang SH, Huang SR, Huang SF, Lin CL. Mechanical response comparison in an implant overdenture retained by ball attachments on conventional regular and mini dental implants: a finite element analysis. Comput Methods Biomech Biomed Engin. 2016;19:911-21.

28. Rezende CE, Chase-Diaz M, Costa MD, Albarracin ML, Paschoeto G, Sousa EA, et al. Stress distribution in single dental implant system: three-dimensional finite element analysis based on an in vitro experimental model. J Craniofac Surg. 2015;26:2196-200.

29. Mobilio N, Stefanoni F, Contiero P, Mollica F, Catapano S. Experimental and numeric stress analysis of titanium and zirconia one-piece dental implants. Int J Oral Maxillofac Implants. 2013;28:e135-42.

30. Chang SH, Lin CL, Hsue SS, Lin YS, Huang SR. Biomechanical analysis of the effects of implant diameter and bone quality in short implants placed in the atrophic posterior maxilla. Med Eng Phys. 2015;2015. Article ID 943839. p. 16

31. Tu MG, Hsu JT, Fuh LJ, Lin DJ, Huang HL. Effects of cortical bone thickness and implant length on bone strain and interfacial micromotion in an immediately loaded implant. Int J Oral Maxillofac Implants. 2010;25:706-14.

32. Lin $\mathrm{CL}$, Lin $\mathrm{YH}$, Chang SH. Multi-factorial analysis of variables influencing the bone loss of an implant placed in the maxilla: prediction using FEA and SED bone remodeling algorithm. J Biomech. 2010;43:644-51.

33. Qian L, Todo M, Matsushita Y, Koyano K. Effects of implant diameter, insertion depth, and loading angle on stress/strain fields in implant/jawbone systems: finite element analysis. Int J Oral Maxillofac Implants. 2009;24:877-86.

34. Karl M, Kelly JR. Influence of loading frequency on implant failure under cyclic fatigue conditions. Dent Mater. 2009;25:1426-32.

35. Hsu JT, Fuh LJ, Lin DJ, Shen YW, Huang HL. Bone strain and interfacial sliding analyses of platform switching and implant diameter on an immediately loaded implant: experimental and three-dimensional finite element analyses. J Periodontol. 2009:80:1125-32.

36. Nagasawa S, Hayano K, Niino T, Yamakura K, Yoshida T, Mizoguchi T, et al. Nonlinear stress analysis of titanium implants by finite element method. Dent Mater J. 2008;27:633-9.
37. Huang HL, Huang JS, Ko CC, Hsu JT, Chang CH, Chen MY. Effects of splinted prosthesis supported a wide implant or two implants: a three-dimensional finite element analysis. Clin Oral Implants Res. 2005;16:466-72.

38. Iplikçioğlu H, Akça K, Cehreli MC, Sahin S. Comparison of non-linear finite element stress analysis with in vitro strain gauge measurements on a Morse taper implant. Int J Oral Maxillofac Implants. 2003;18:258-65.

39. Chang CL, Chen CS, Yeung TC, Hsu ML. Biomechanical effect of a zirconia dental implant-crown system: a three-dimensional finite element analysis. Int J Oral Maxillofac Implants. 2012;27:e49-57.

40. Chang $\mathrm{CL}$, Chen $\mathrm{CS}$, Huang $\mathrm{CH}$, Hsu ML. Finite element analysis of the dental implant using a topology optimization method. Med Eng Phys. 2012;34:999_ 1008.

41. Zhiyong L, Arataki T, Shimamura I, Kishi M. The influence of prosthesis designs and loading conditions on the stress distribution of tooth-implant supported prostheses. Bull Tokyo Dent Coll. 2004:45:213-21.

42. Chang JZ, Chen YJ, Tung YY, Chiang YY, Lai EH, Chen WP, et al. Effects of thread depth, taper shape, and taper length on the mechanical properties of mini-implants. Am J Orthod Dentofac Orthop. 2012;141:279-88.

43. Inglam S, Chantarapanich N, Suebnukarn S, Vatanapatimakul N, Sucharitpwatskul S, Sitthiseripratip K. Biomechanical evaluation of a novel porous-structure implant: finite element study. Int J Oral Maxillofac Implants. 2013;28:e48-56.

44. Necchi S, Migliavacca F, Gastaldi D, Pizzagalli M, Del Fabbro M, Weinstein R, et al. The effect of fixture neck design in a realistic model of dental implant: a finite element approach. Comput Methods Biomech Biomed Engin. 2003;6:289-97.

45. Genna F. On the effects of cyclic transversal forces on osseointegrated dental implants: experimental and finite element shakedown analyses. Comput Methods Biomech Biomed Engin. 2003;6:141-52.

46. Perriard J, Wiskott WA, Mellal A, Scherrer SS, Botsis J, Belser UC. Fatigue resistance of ITI implant-abutment connectors - a comparison of the standard cone with a novel internally keyed design. Clin Oral Implants Res. 2002;13:542-9.

47. Sotto-Maior BS, Mercuri EG, Senna PM, Assis NM, Francischone CE, Del Bel Cury AA. Evaluation of bone remodeling around single dental implants of different lengths: a mechanobiological numerical simulation and validation using clinical data. Comput Methods Biomech Biomed Engin. 2016;19:699-706.

48. Wang C, Li Q, McClean C, Fan Y. Numerical simulation of dental bone remodeling induced by implant-supported fixed partial denture with or without cantilever extension. Int J Numer Method Biomed Eng. 2013;29:1134-47.

49. MacGinnis M, Chu H, Youssef G, Wu KW, Machado AW, Moon W. The effects of micro-implant assisted rapid palatal expansion (MARPE) on the nasomaxillary complex — a finite element method (FEM) analysis. Prog Orthod. 2014;15:52.

50. Choi KS, Park SH, Lee JH, Jeon YC, Yun MJ, Jeong CM. Stress distribution on scalloped implants with different microthread and connection configurations using three-dimensional finite element analysis. Int J Oral Maxillofac Implants. 2012;27:e29-38.

51. Shen WL, Chen CS, Hsu ML. Influence of implant collar design on stress and strain distribution in the crestal compact bone: a three-dimensional finite element analysis. Int J Oral Maxillofac Implants. 2010;25:901-10.

52. Lin D, Li Q, Li W, Duckmanton N, Swain M. Mandibular bone remodeling induced by dental implant. J Biomech. 2010;43:287-93.

53. Fanuscu MI, Vu HV, Poncelet B. Implant biomechanics in grafted sinus: a finite element analysis. J Oral Implantol. 2004;30:59-68.

54. Mellal A, Wiskott HW, Botsis J, Scherrer SS, Belser UC. Stimulating effect of implant loading on surrounding bone. Comparison of three numerical models and validation by in vivo data. Clin Oral Implants Res. 2004;15:239-48.

55. Zarone F, Apicella A, Nicolais L, Aversa R, Sorrentino R. Mandibular flexure and stress build-up in mandibular full-arch fixed prostheses supported by osseointegrated implants. Clin Oral Implants Res. 2003;14:103-14.

56. Bulaqi HA, Mousavi Mashhadi M, Geramipanah F, Safari H, Paknejad M. Effect of the coefficient of friction and tightening speed on the preload induced at the dental implant complex with the finite element method. J Prosthet Dent. 2015:113:405-11.

57. Vayron R, Nguyen VH, Bosc R, Naili S, Haïat G. Finite element simulation of ultrasonic wave propagation in a dental implant for biomechanical stability assessment. Biomech Model Mechanobiol. 2015;14:1021-32.

58. Cicciù M, Cervino G, Bramanti E, Lauritano F, Lo Gudice G, Scappaticci L, et al. FEM analysis of mandibular prosthetic overdenture supported by dental implants: evaluation of different retention methods. Comput Math Methods Med. 2015;2015:16. http://dx.doi.org/10.1155/2015/943839. 
59. Topkaya T, Solmaz MY. The effect of implant number and position on the stress behavior of mandibular implant retained overdentures: a threedimensional finite element analysis. J Biomech. 2015;48:2102-9.

60. Costa C, Peixinho N, Silva JP, Carvalho S. Study and characterization of the crest module design: a 3D finite element analysis. J Prosthet Dent. 2015;113:541-7.

61. Arat Bilhan S, Baykasoglu C, Bilhan H, Kutay O, Mugan A. Effect of attachment types and number of implants supporting mandibular overdentures on stress distribution: a computed tomography-based 3D finite element analysis. J Biomech. 2015;48:130-7.

62. Abou-Emara M, Spintig T, Lackmann J, Müller WD. Finite element analysis of the biomechanical effects of PEEK dental implants on the peri-implant bone. J Biomech. 2015;48:1-7.

63. Capek L, Simunek A, Henys P, Dzan L. The role of implant's surface treatment to its preload. Comput Methods Biomech Biomed Engin. 2014;17(Suppl 1):8-9.

64. Brunski JB. Biomechanical aspects of the optimal number of implants to carry a cross-arch full restoration. Eur J Oral Implantol. 2014;7(Suppl 2):S111-31.

65. Harirforoush R, Arzanpour S, Chehroudi B. The effects of implant angulation on the resonance frequency of a dental implant. Med Eng Phys. 2014;36:1024-32.

66. Xiao W, Li Z, Shen S, Chen S, Wang Y, Wang J. Theoretical role of adjunctive implant positional support in stress distribution of distal-extension mandibular removable partial dentures. Int J Prosthodont. 2014;27:579-81.

67. Kim S, Kim S, Choi H, Woo D, Park YB, Shim JS, et al. A three-dimensional finite element analysis of short dental implants in the posterior maxilla. Int J Oral Maxillofac Implants. 2014:29:e155-64.

68. van Staden RC, Li X, Guan H, Johnson NW, Reher P, Loo YC. A finite element study of short dental implants in the posterior maxilla. Int J Oral Maxillofac Implants. 2014;29:e147-54.

69. Piotrowski B, Baptista AA, Patoor E, Bravetti P, Eberhardt A, Laheurte P. Interaction of bone-dental implant with new ultra low modulus alloy using a numerical approach. Mater Sci Eng C Mater Biol Appl. 2014;38:151-60.

70. dos Santos MB, Bacchi A, Correr-Sobrinho L, Consani RL. The influence of clip material and cross sections of the bar framework associated with vertical misfit on stress distribution in implant-retained overdentures. Int J Prosthodont. 2014;27:26-32

71. Santiago Junior JF, Pellizzer EP, Verri FR, de Carvalho PS. Stress analysis in bone tissue around single implants with different diameters and veneering materials: a 3-D finite element study. Mater Sci Eng C Mater Biol Appl. 2013;33:4700-14

72. Ding $X$, Liao SH, Zhu XH, Wang HM. Influence of orthotropy on biomechanics of peri-implant bone in complete mandible model with full dentition. Biomed Res Int. 2014;2014:709398.

73. Gačnik F, Ren Z, Hren NI. Modified bone density-dependent orthotropic material model of human mandibular bone. Med Eng Phys. 2014;36:1684-92.

74. Kang N, Wu YY, Gong P, Yue L, Ou GM. A study of force distribution of loading stresses on implant-bone interface on short implant length using 3-dimensional finite element analysis. Oral Surg Oral Med Oral Pathol Oral Radiol. 2014;118:519-23.

75. Chi SW, Hodgson J, Chen JS, Reggie Edgerton V, Shin DD, Roiz RA, et al. Finite element modeling reveals complex strain mechanics in the aponeuroses of contracting skeletal muscle. J Biomech. 2010;43:1243-50.

76. Yucesoy CA, Koopman BH, Huijing PA, Grootenboer HJ. Three-dimensional finite element modeling of skeletal muscle using a two-domain approach: linked fiber-matrix mesh model. J Biomech. 2002;35:1253-62.

77. Koolstra JH, van Eijden TM. A method to predict muscle control in the kinematically and mechanically indeterminate human masticatory system. J Biomech. 2001;34:1179-88.

78. Koolstra JH, van Eijden TM. Combined finite-element and rigid-body analysis of human jaw joint dynamics. J Biomech. 2005;38:2431-9.

79. Houdijk H, Bobbert MF, de Haan A. Evaluation of a Hill based muscle model for the energy cost and efficiency of muscular contraction. J Biomech. 2006;39:536-43.

80. Maeda Y, Wood WW. Finite element method simulation of bone resorption beneath a complete denture. J Dent Res. 1989;68:1370-3.

\section{Submit your manuscript to a SpringerOpen ${ }^{\circ}$ journal and benefit from:}

- Convenient online submission

- Rigorous peer review

- Open access: articles freely available online

- High visibility within the field

- Retaining the copyright to your article

Submit your next manuscript at $\boldsymbol{\nabla}$ springeropen.com 